By KENNETH S. GAPP

\title{
The Librarian's Task in Improving Personnel
}

The librarian of Princeton Theological Seminary discusses factors making for staff members' growth in service.

$\mathrm{T}$ HE MOST pressing personnel problem in the library profession, as we face it in some important recent appointments, appears to be the problem of the mature librarian. The librarian in service must be kept at the peak of efficiency and must develop a comprehensive ability to master the educational situation which confronts our libraries. The library has been the center of instruction for students and faculty. Can the library now develop an aggressive program for employing its own resources and its contacts with instruction and research to improve the quality of its own personnel? The preliminary training of librarians in college and professional schools occupies comparatively few years. Decisive as it may be in many instances, even more important are the educational influences which surround the librarian throughout his later career. Consequently, the administrative librarian bears the main responsibility for keeping such educational forces active in the profession.

\section{Selection of Candidates}

The librarian has a unique opportunity for picking out, early in their college career, students who give promise of unusual ability for library service. The usual criteria of social and educational background, personality, and administrative ability will, of course, weigh heavily in his judgment of candidates for librarianship. Yet the personal contacts of the librarian with students make it possible for him to weigh the more vital and intangible factors of personality. Among these factors stress should fall upon the possession of the right kind of scholarly abilities and on some promise of the ability to correlate library services with various fields of knowledge and with educational procedures.

\section{Depth vs. Breadth of Scholarship}

In recent years the necessity for sound scholarship has frequently been stressed. The academic course of the librarian must lead to a knowledge of more or less extensive fields of learning and to a real understanding of what goes on behind the scenes of scholarly work. This scholarship must not be mere pedantry. A scholarship which stresses the relevance of knowledge and research to the intellectual and social structure of our times is needed. It is precisely in this respect that intensity of scholarship in one field can contribute very directly to the comprehension of the fundamental relation which the library has toward the processes of scholarship. But in actual practice in the training of personnel a serious difficulty has arisen because depth of scholarship has seemed 
to be antagonistic to the wide comprehension of knowledge which is so essential to competent library service. One cause for this may be that too little attention has been paid by both instructors and librarians to the points of contact between a specialized subject knowledge and allied fields of learning. Subject knowledge, when viewed in the light of its relation to allied fields of thought, can open a direct path to broad and comprehensive learning, if the scholar, starting from his specialty, extends his knowledge in ever widening circles. The extension of knowledge to many fields is indeed valuable for librarians who supervise special and departmental libraries, but it is absolutely essential for librarians who serve in university and research libraries. Survey courses, however useful they may be in presenting a background of general information during the first two years of college, would appear to be insufficient to guarantee this end, because in themselves they fail to provide for any depth of learning. Therefore, candidates for librarianship, in addition to a broad cultural background, should acquire a type of scholarship which stresses the relation of a subject specialty to allied fields of learning, and which reveals the vital relationship of scholarship to the structure of our times.

It would appear, in the majority of American universities and graduate schools, that this end can rarely be achieved without the aid of a direct contribution by librarians to the intellectual life of the students. If the needed factors cannot be incorporated in the educational program of the whole institution, the objective must be achieved at least for possible candidates for librarianship. Here the librarian bears the responsibility for the selection and early training of his future colleagues. Suitable persons, who possess the general qualifications for librarianship, can be singled out for personal supervision, with a view to developing the intellectual characteristics which library work demands. Some of the influence of the librarian may, perhaps, be exerted in the form of counsel regarding curricular studies. Yet, more general assistance may be given, without specifically basing the appeal on the requirements of library work, by influencing the outlook of the student toward his studies, and by actively urging the acquisition of necessary qualities as desirable possessions of general learning.

\section{Capacity for Growth}

When a candidate apparently possesses specialized subject knowledge and gives evidence of some ability to extend his learning widely into all fields of scholarship, his prospects for future achievement must be weighed. Wide knowledge in an accurate form appears to be the possession of only the older librarian who has spent many wise years in service. Even more important than the mere possession of various static qualifications is a certain curiosity, an intellectual and emotional drive, which gives some guarantee of future growth. The capacity for growth is something that is very hard to measure in any given individual. It probably can best be measured through a personal interview in which considerable attention is paid to the individual's plans and undertakings, to his awareness of the most recent developments in various fields and to his ability to discuss critically and with sound judgment the newest topics of interest. Careful selection will be needed to obtain librarians whose abilities 
will increase with age and experience.

Careful consideration should be given to the candidate's prospects of developing the ability to adapt library routines to desirable educational objectives. At present there would appear to be no satisfactory procedure for judging this ability in the early stages of training. However, it should be noted that students who do have a general capacity for this correlation will at first view librarianship with an outlook already integrated around factors unrelated to library work. Consequently, these students may at first seem more hostile to librarianship than others. The crucial issue is whether or not these students are willing to achieve a reintegration which gives full play to the professional library outlook. At this point the influence of the librarian may be most helpful by thorough discussion of the relation of routines to knowledge, the social structure, and educational objectives. If this process of reintegration is undertaken early enough and is wisely effected, the candidate presumably will retain much of the vitality of his scholarship for use in his librarianship.

It is indeed difficult for the librarian to judge students from the point of view of these qualifications for library service. Yet an adequate opportunity for a close study of personality as well as for careful supervision of student outlook is possible in the case of the students employed in the library. The accepted practice of giving to these students merely clerical work tends to create in their minds the illusion that librarianship is concerned essentially with routines. This misunderstanding may lead to a situation in which the contacts between librarian and student are restricted to routine matters, and which for that very reason eventually may cause a serious error in judgment regarding the qualifications of students for library service. It would appear to be essential, therefore, that a considerable part of the librarian's contacts with student assistants should be above the level of routine labor. If elementary professional tasks cannot be entrusted to them, sufficient instruction in the general nature of the librarian's work should be given to them in order to guarantee a correct understanding of the higher aims of librarianship. This policy will often interest more students in librarianship, and will, in many cases, lead to a sounder judgment by the librarian regarding their suitability for library service. In any case, it will result in an increased understanding of library objectives in later life, when the members of the student staff enter upon positions of influence.

\section{Specific Procedures with Staff}

The skilful librarian can so administer the staff that the qualities which tend to produce competent librarians are continuously enhanced through years of service. A few general procedures which may lead to these results merit attention. The discussion with the staff of the main advances in professional research, of the developments in techniques, of policy, and of educational objectives keeps alive interest in the newer phases of library service. Staff meetings and conferences are useful, particularly if the critical approach to librarianship is stressed. The librarian must try to obtain for himself and his staff complete mastery of whatever proves effective in the way of technical routines. If routine methods are not fully mastered, they tend to become objectives in themselves, and either through inefficiency or inadaptability may block progress in the 
more important sphere of educational life.

Moreover, the librarian must endeavor to maintain himself and his staff in the very center of the intellectual and cultural influences of modern life. The pressure of routine processes dares not lead to a routine approach to the problems of knowledge. Among the most important procedures for keeping the staff intellectually competent is the practice of urging members of the staff to take advanced courses in some subject in which they show interest. Study under the close supervision of competent professors aids greatly in the acquisition of knowledge in an orderly form, and tends to develop the ability for a more independent scholarship. In libraries which stress subject fields the successful completion of several graduate courses would seem to be essential for competent service. Furthermore, the library has within its own walls extensive resources for deepening the intellectual outlook of its staff. Much has been written of the necessity that time be granted from working hours for reading, that librarians might well ask for reading periods and for leaves of absence for the purpose of continuing their education. All of these opportunities probably will be available to librarians in future years, provided such privileges can be used to bring to full fruition contributions which have already been initiated by the staff. It will be extremely difficult, if not impossible, to obtain these opportunities for concentrated study if they are claimed for beginning work which will be of value only in the distant future. Consequently, the responsibility for initiating study falls directly upon librarians themselves. No matter what the cost, the librarian must now give pledge of future accomplishment in scholarship, if he wishes to obtain the time for leisurely study. Then, in the fight for shorter working hours and improved working conditions, the general improvement of personnel can be offered in place of hours of routine labor. The scholarly influences which have been initiated in supervised study must now be fanned into flame in the midst of the routine which strives to kill it.

But the emphasis upon scholarship dare not lead to a subordination of technical and administrative ability. The history of the development of technical service has indeed been largely determined by the policy of minimizing the importance of learning in order to cast into brilliant focus routines which, by reason of the special emphasis placed upon them, have been developed to some degree of efficiency. The very history of the attempt to eliminate scholarship reveals the possibility that extensive learning can now be reincorporated into the professional outlook.

\section{Correlation}

An unusual opportunity for developing the abilities of the staff may be found in the effort to correlate the services of the library with the new demands in instruction and research. In the effort to adapt the library to meet the demands of contemporary thought, the librarian may call upon members of the staff to specialize in the various subject and functional approaches to knowledge. Thus, the circulation librarian is concerned with seeing that the demands for material under conditions conducive to study are met; the reference librarian that the newer developments in research are accompanied by corresponding developments in reference materials and techniques; the order librarian that the needs of instruction and research are adequately served by the 
books purchased; the catalogers that recent developments in the various fields of knowledge bear fruit in the revision of classification and subject headings. The process of reintegration of techniques with knowledge will involve the extensive study of knowledge under the guidance of specialists, the unbiased analysis of the needs to be met, and the careful appraisal of the technical means to achieve the desired result in specific departments of library service. This process is closely related to the routine tasks of the staff, and yet it can frequently be transformed into a definite educational program by requiring the staff to undertake each phase of the process under the careful supervision of subject and library specialists.

\section{Contacts with Faculty}

Furthermore, the librarian will endeavor to maintain every possible contact with the faculty, both for himself and for his staff. Relations with the faculty must be far more intimate than is usually implied in the word "cooperation." In this connection may be noted the opinion of Harvie Branscomb, who has prepared for the Association of American Colleges a study of the effectiveness of college and university libraries just published by the A.L.A. He raises the question whether or not the administration of college libraries is to a sufficient degree educationally conscious to cooperate adequately with efforts to make the library fulfil a larger share of educational responsibility. If his criticism has any basis in fact, librarians must indeed become complete masters of all areas of thought and endeavor where cooperation between the library and the faculty may at any time develop. This mastery of the areas of cooperation can be achieved only by extending very wide- ly the knowledge of that broad area of learning and educational policy which both the scholar and the librarian share, for it is specifically in this area of knowledge, common to both librarian and professor, that the need for cooperation has its origin. The easiest way of achieving this competence is to maintain the most cordial relation with professors in every field which touches upon library service. Close contact with specialists is also useful in those activities which have apparently no immediate bearing on library affairs, for the knowledge and understanding acquired in the less relevant fields is not cast into the usual mold of the librarian's outlook and therefore is potentially more effective in interpreting the mind of the faculty.

In some cases it may be possible for the librarian to select a promising member of his staff for special training as an understudy to his own position. Such an understudy can be given extensive guidance in the administrative control of all phases of work, in technical knowledge, and in the correlation of library facilities with the educational requirements of the institution. In view of a possible threat to the position of the librarian supervising the understudy, it might be well to seek a definite understanding with the administrative board. In any case, this procedure would clearly appear to be the special responsibility of those librarians who are approaching the retirement age. The selection of an understudy no doubt presents great difficulties. Nevertheless, the procedure of judging subordinates largely on the basis of their usefulness within the administrative body frequently leads to an underestimation or repression of their administrative capabilities. Clearly, a method of developing administrative ability among subordinates with- 
out disrupting the existing administrative control must be found by progressive librarians.

These factors which have been discussed from a very general point of view must, in any one library, be translated into specific norms which are pertinent to the library concerned. A major task of the administrative librarian is to clarify and reveal to his staff the fundamental criteria of excellence in service and the real basis for advancement in salary and rank. The head librarian must, of course, seek this clarification from his president, and supplement it, if necessary, from his knowledge of his own organization and of conditions in other scholarly libraries. $\mathrm{He}$ must incorporate in these criteria of ex. cellence factors which go far beyond routines and administration, which deal directly with the fundamental problems and outlook of scholarship. There are, no doubt, many librarians now in the profession who, if reminded frankly of the real criteria upon which advancement depends, will rise to positions of superior rank. It is the librarian's task to see that our libraries provide the influences which create eminence of personnel in librarianship.

\section{Summary}

The responsibility of the librarians for selecting and training personnel is discussed with emphasis upon factors which tend to produce competent librarians after years of service. Scholarship, the capacity for growth, and the ability to correlate library services are emphasized in relation to selection and early training of students. Among various procedures for continuing the education of the staff are mentioned discussion, advanced study, the training of an understudy, emphasis upon the correlation of services with scholarly and educational needs, and the clarification of the criteria of excellent service.

\section{References}

Branscomb, Harvie. "Teaching with Books." Library Journal 64:391-94, May 15, I939.

Carnovsky, Leon. "Why Graduate Study for Librarianship?" Library Quarterly 7:246-6I, Apr. I937.

Fay, Lucy. "Continuing Education of the College Library Staff." Library Journal 62:199-201, Mar. I, 1937.

Harvard University. Special Committee Appointed by the President. Report on Some Problems of Personnel in the Faculty of Arts and Sciences. Harvard University Press, 1939.

Mitchell, Sydney B. "Essentials in the Training of University Librarians." College and Research Libraries I :22-29, Dec. 1939.

Munn, Ralph. Conditions and Trends in Education for Librarianship. Carnegie Corporation of New York, 1936.

Williamson, C. C. Training for Library Service. Carnegie Corporation of New York, 1923.

Wilson, Louis R. "Essentials in the Training of University Librarians." College and Research Libraries I:I3-2I, Dec. I 939 . 